Article

\title{
Preparation and Self-Healing Properties of Clinker/PVP Microsphere in Cement Paste
}

\author{
Jun Li, Zhengwu Jiang * and Wenting Li
}

Key Laboratory of Advanced Civil Engineering Materials of Ministry of Education, School of Materials Science and Engineering, Tongji University, Shanghai 201804, China; 1610421@tongji.edu.cn (J.L.);

lwt@tongji.edu.cn (W.L.)

* Correspondence: jzhw@tongji.edu.cn; Tel.: +86-21-6958-2140

Received: 26 December 2019; Accepted: 23 January 2020; Published: 27 January 2020

\begin{abstract}
This paper presents a new insight into the autolytic mineral self-healing method for cementitious materials. The clinker/PVP (polyvinyl pyrrolidone) autolytic microsphere was prepared via the film coating method with cement clinker as a healing agent and PVP as the autolytic coating film. The morphology and chemical structure of the microsphere were characterized by environmental scanning electron microscopy (FESEM) equipped with energy dispersive spectrometer (EDS) and Fourier transform infrared spectroscopy (FTIR), respectively. The clinker retaining original mineral healing composition was successfully coated with a PVP film confirmed by FTIR. The maximum film thickness was $7.54 \mu \mathrm{m}$, which was determined by laser particle size measurement. The autolytic behavior was measured using isothermal calorimetry and successfully controlled by pretreatment degree (i.e., silane coupling agent amount). Experimental results showed that the compressive strength recovery of cement paste with a $30 \%$ microsphere was $54 \%$ higher than ordinary cement paste specimens. The damage degree of the specimen was also decreased by adding the autolytic microsphere.
\end{abstract}

Keywords: autolytic mineral self-healing; clinker; film coating; autolytic behavior

\section{Introduction}

Concrete is the most widely used material in modern construction since Portland cement was developed in the 1820s. Concrete has outstanding properties in terms of high compressive strength, excellent molding performance and low cost. However, cracks in concrete structure occur easily because of its relatively low flexural strength compared to its high compressive strength [1,2]. The cracking of concrete structures is the most important factor causing or accelerating the major deteriorating processes of reinforced concrete, such as alkali-aggregate reactions, sulfate erosion and steel bar corrosion. Many hazardous substances permeate these cracks with water, especially those cracks which connect with each other, thus causing the deterioration of the concrete and shortening the structure service life $[3,4]$. Although man-made repair is a conventional solution, problems ae often encountered in repair work resulting from not-visible or inaccessible cracks, or structures in complex environments [5-7]. Moreover, it is high-cost and high-labor operation work which only lasts 10-15 years [8-10]; thus, there are calls for a more sustainable approach [11-13]. Considering this, crack self-healing would be more effective. The well-known autogenous self-healing is actually a natural phenomenon of cementitious materials [14]. Limited crack width is healed mainly due to the mechanism of the further hydration of unhydrated cement, or the carbonation of calcium hydroxide $\left(\mathrm{Ca}(\mathrm{OH})_{2}\right)$. The younger samples present better self-healing effectiveness [15]. In addition, the healing efficiency of autogenous healing is poor and difficult to control [4]. 
Therefore, there are many healing methods which have been designed to enhance autogenous self-healing, including the addition of mineral admixtures, bacteria and adhesive agents [16-18]. Based on whether there is any host-guest reaction, mineral self-healing can be classified as intrinsic healing, which presents better compatibility [19-21]. Furthermore, the permeability and strength recovery of mineral self-healing are more effective [22-24]. However, there are several problems that challenge mineral self-healing, in which uncontrollable healing time is one of them. Therefore, inspired by the autolysis of biological cells, the autolytic mineral self-healing method has been proposed in previous groups' research [25]. The autolytic mineral self-healing method is similar to the process of cell autolysis that refers to self-destruction by its enzyme. The autolytic microsphere used in this method consists of the internal healing substance and the external protective coating film. The healing substance can be a mineral material, such as cement clinker, or a monomineral that can produce healing products like C-S-H-which has a certain strength and great compatibility with the cementitious materials.

This paper presents the preparation and self-healing characterization of a clinker/PVP autolytic microsphere. The microsphere consists of cement clinker as a healing agent and polyvinyl pyrrolidone (PVP) as a film to avoid premature consumption [26]. Clinker is a suitable and compatible mineral since it is the main raw material of concrete. Moreover, PVP film can withstand the shear force due to its high tensile strength, so that coating film will not be broken in the mix procedure [27-29]. Silane coupling agent is chosen as the molecular bridge between the inorganic (i.e., clinker) and organic (i.e., PVP) matrix. Potential use of clinker as a self-healing constituent was investigated by a researcher. The possible self-healing phenomena were detected using hydration products and the recovery of strength, even though only a preliminary step was conducted [30].

In this study, the clinker was treated with silane coupling agent and then coated with an autolytic film. The morphology and chemical structure of the autolytic microsphere were determined. The film thickness was also measured. In addition, the self-healing effectiveness was evaluated via measurement of compressive strength recovery and a damage degree test.

\section{Materials and Methods}

\subsection{Materials}

All reagents used in this experiment were produced from Sinopharm Chemical Reagent Co., Ltd. (Shanghai, China) Polyvinyl pyrrolidone (PVP) in analytic grade was chosen as the film material. Silane coupling agent ( $\gamma$-aminopropyl triethoxysilane, $\mathrm{KH}-550)$ was used as a surface pretreatment agent for the cement clinker-the surface pretreatment agent which was chosen to form the active binding layer on the surface of clinker. The chemical composition of cement clinker was shown in Table 1.

Table 1. Chemical composition of cement clinker.

\begin{tabular}{ccccccccc}
\hline $\mathrm{CaO}$ & $\mathrm{SiO}_{2}$ & $\mathrm{Fe}_{2} \mathrm{O}_{3}$ & $\mathrm{Al}_{2} \mathrm{O}_{3}$ & $\mathrm{MgO}$ & $\mathrm{SO}_{3}$ & $\mathrm{Na}_{2} \mathrm{O}$ & $\mathrm{K}_{2} \mathrm{O}$ & Other \\
\hline 63.1 & 24.1 & 3.27 & 4.34 & 1.16 & 0.76 & 0.12 & 0.8 & 2.35 \\
\hline
\end{tabular}

\subsection{Preparation of clinker/PVP Microsphere}

The clinker/PVP autolytic mineral self-healing microspheres were prepared through several procedures. The main procedure was as follows: (1) the solution with $100 \mathrm{~g}$ cement clinker and $100 \mathrm{~mL}$ ethanol was stirred at $60{ }^{\circ} \mathrm{C}$ for $5 \mathrm{~min}$. Then $3 \mathrm{~g}$ silane coupling agent $\mathrm{KH}-550$ (except isothermal calorimetry test in Section 2.4.4) was added and the solution was stirred at $600 \mathrm{r} / \mathrm{min}$ for $30 \mathrm{~min}$. After being kept for 1 hour, the pretreated clinker was obtained through filtering and drying. (2) A certain amount of PVP was dissolved in $300 \mathrm{~mL}$ ethanol and stirred to disperse for several minutes. Then, the solution was stirred for half an hour with the addition of pretreated clinker at $70{ }^{\circ} \mathrm{C}$. Finally, the clinker/PVP autolytic microsphere was obtained by filtering and drying. During the preparation 
process, the mass ratio of PVP to clinker was changed to determine the thickness of the protective coating film shown in Table 2.

Table 2. Proportion used for preparation of coating film.

\begin{tabular}{cccccccc}
\hline Description & No. $\mathbf{1}$ & No. $\mathbf{2}$ & No. $\mathbf{3}$ & No. $\mathbf{4}$ & No. $\mathbf{5}$ & No. $\mathbf{6}$ & No. $\mathbf{7}$ \\
\hline PVP/clinker ratio & $0 \%$ & $1 \%$ & $2 \%$ & $4 \%$ & $5 \%$ & $10 \%$ & $15 \%$ \\
\hline
\end{tabular}

\subsection{Mix Proportion and Specimen Preparation}

The chemical composition of the type 525 ordinary Portland cement used is shown in Table 3 . Cement paste with $0.35 \mathrm{w} / \mathrm{c}$ and dimensions of $25 \times 25 \times 25 \mathrm{~mm}$ was prepared. The replacement of clinker/PVP microsphere was $10 \%, 20 \%$ and $30 \%$ by mass of cement as shown in Table 4 . The Mixing procedure was performed in accordance with Chinese standards (GBT 1346-2011). The hardened paste was demolded after $24 \mathrm{~h}$ and subsequently cured in a curing room $\left(20 \pm 2{ }^{\circ} \mathrm{C}\right.$ and $\left.\mathrm{RH}>95 \%\right)$ until the testing day. At the age of 28 days, the specimens were pre-cracked using pre-compression to cause distributed microcracks [22]. The pre-compression load was held at $80 \%$ of the average ultimate resistance of three cubic specimens from the same batch. The total nine pre-cracked specimens of each content were placed in water with a temperature of $20 \pm 2{ }^{\circ} \mathrm{C}$ until the following test day, and three pre-cracked specimens were used for each test age.

Table 3. Chemical composition of Portland cement.

\begin{tabular}{ccccccccccc}
\hline Component & $\mathrm{SiO}_{2}$ & $\mathrm{Al}_{2} \mathrm{O}_{3}$ & $\mathrm{Fe}_{2} \mathrm{O}_{3}$ & $\mathrm{CaO}$ & $\mathrm{MgO}$ & $\mathrm{TiO}_{2}$ & $\mathrm{SO}_{3}$ & $\mathrm{Na}_{2} \mathrm{O}$ & $\mathrm{K}_{2} \mathrm{O}$ & $\mathrm{LOI}$ \\
\hline Content (wt.\%) & 20.0 & 4.51 & 3.11 & 64.3 & 0.68 & 0.22 & 2.99 & 0.03 & 0.72 & 2.70 \\
\hline
\end{tabular}

Table 4. Mixture proportion for test.

\begin{tabular}{ccccc}
\hline Description & w/c & $\begin{array}{c}\text { Microsphere Fraction (wt. } \\
\text { \% with Cement) }\end{array}$ & $\begin{array}{c}\text { Specimens } \\
\text { Number }\end{array}$ & Test Method \\
\hline \multirow{3}{*}{ Compression } & 0.35 & 0 & 3 & \\
& 0.35 & 10 & 3 & For ultimate resistance \\
& 0.35 & 20 & 3 & \\
Pre-compression & 0.35 & 30 & 3 & For strength recovery \\
& 0.35 & 0 & 9 & and pulse test \\
\hline
\end{tabular}

\subsection{Test Procedure}

\subsubsection{Morphology of Microsphere}

The morphology of the microsphere was observed using an environmental scanning electron microscopy (ESEM, Quanta 200F) (FEI company, Oregon State, Hillsboro, USA) equipped with an energy dispersive spectrometer (EDS) (FEI company, Oregon State, Hillsboro, USA). The prepared autolytic microspheres were mixed into the cement paste, and the specimen was taken immediately for BSE-SEM observation after preliminary hardening.

\subsubsection{Chemical Structure of Microsphere}

Fourier transform infrared spectroscopy (FTIR) (Bruker Optics, Karlsruhe, Germany) was used to determine the chemical structures of the clinker/PVP autolytic microsphere in order to identify the validity of film coating method. 


\subsubsection{Coating Film Thickness}

The autolytic microspheres were subjected to laser particle size analysis (LS320) (Beckman Coulter, California State, Brea, CA, USA). The average particle size was regarded as the diameter of the microspheres, and the formula for the coating film thickness is shown in Equation (1).

$$
\mathrm{T}=\left(\mathrm{D}_{\mathrm{m}}-\mathrm{D}_{0}\right) / 2
$$

where $T$ is coating film thickness $(\mu \mathrm{m}), \mathrm{D}_{\mathrm{m}}$ is the particle diameter of microspheres $(\mu \mathrm{m})$, and $\mathrm{D}_{0}$ is the particle diameter of cement clinker $(\mu \mathrm{m})$.

\subsubsection{Autolytic Behavior}

The autolytic time, defined as the time required for complete the autolysis of the coating film, is proposed to describe the autolytic behavior of microsphere [25]. The autolytic time is calculated as the time difference between the occurrence of two hydration exothermic heat peaks (reference and microsphere sample) according to equation (2). Therefore, the heat flow of paste was measured using isothermal calorimetry based on the Chinese standard GB12959-2008. These measurements of clinker and autolytic microsphere with $0 \mathrm{~g}, 1 \mathrm{~g}, 3 \mathrm{~g}, 5 \mathrm{~g}$ silane coupling agent (noted as SCA-0, SCA-1, SCA-3, SCA-5 respectively) were performed at $20^{\circ} \mathrm{C}$.

$$
\mathrm{T} \gamma=\mathrm{Ta}-\mathrm{Tr}
$$

where $\mathrm{T} \gamma$ is the autolytic time ( $\mathrm{min}$ ), Ta is the time corresponding to the hydration exothermic peak of (clinker and water) paste ( $\mathrm{min}), \mathrm{Tr}$ is the time corresponding to the hydration exothermic peak of (microsphere and water) paste (min).

\subsubsection{Strength Recovery and Damage Degree of Self-Healing Specimens}

A compressive strength test was performed to evaluate the self-healing effectiveness. The pre-cracked specimens were reloaded until failure to determine the strength recovery after water curing age of 2 days, 14 days and 28 days. The compressive strength recovery is determined by Equation (3).

$$
\gamma=\mathrm{P}_{\mathrm{e}} / \mathrm{P}_{\mathrm{c}}
$$

where $\gamma$ is the compressive strength recovery (\%), Pe is the ultimate compressive strength in reloading $(\mathrm{MPa}), \mathrm{Pc}$ is the initial compressive strength $(\mathrm{MPa})$.

The self-healing ability was also determined using the ultrasonic transmission method. Previous studies [31] showed that changes of ultrasonic properties can reflect the internal damage of cementitious materials, since the microstructure of materials will affect the ultrasonic transmission. Therefore, the damage degree was calculated according to Equation (4) to evaluate the recovery of internal closure, determined using an acoustic emission pulse test. The pulse transmission direction was vertical to the compression load direction. It is noted that the pulse test was conducted immediately after the pre-cracking of specimens and then carried out at the same day as the compressive strength test. The same specimens were used for both experiments, since the acoustic emission pulse test is a non-destructive experiment.

$$
\mathrm{D}=1-\left(\mathrm{T}_{0} / \mathrm{T}_{\mathrm{h}}\right)^{2}
$$

where $\mathrm{D}$ is the damage degree, $\mathrm{T}_{0}$ is the pulse time of specimen before pre-compression, Th is the pulse time of specimen after self-healing. 


\section{Results}

\subsection{Characterization of Clinker/PVP Microsphere}

\subsubsection{Morphology and Microstructure Analysis}

The prepared autolytic microsphere was mixed into the cement paste and the backscattering specimen was prepared after preliminary hardening. The results of BSE-SEM observation are shown in Figure 1.

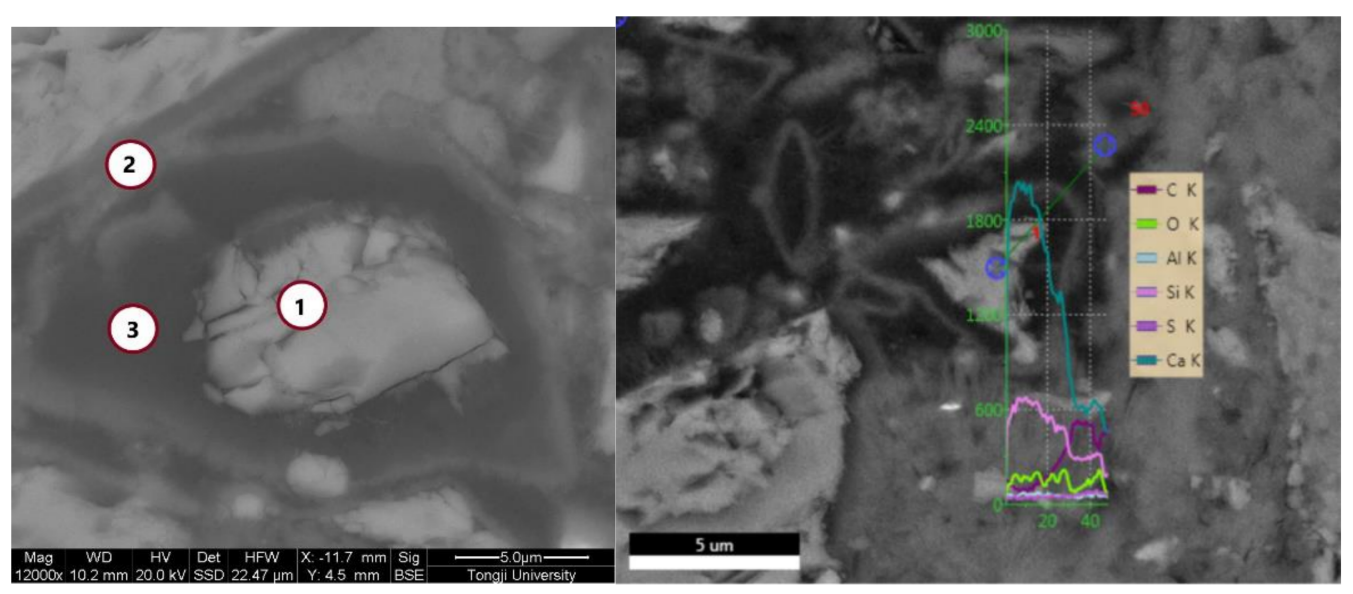

(a)

(b)

Figure 1. Micro-morphology of autolytic microspheres by BSE-SEM (a) Spot analysis; (b) Line analysis.

Based on the BSE-SEM imaging principle, the BSE-SEM imaging brightness is determined by the average atomic number. The region with a higher average atomic number presents a stronger backscattered electron signal and exhibits a brighter gray scale in the BSE images [32]. The results in Figure 1(a) show that the whole autolytic microsphere presents irregular shape. This is mainly due to the shape of the clinker. The brightest material in the middle is the remaining cement clinker, which is the healing agent. To further confirm the dark materials are PVP film, the chemical composition measured by spot and line analysis of the EDS are shown in Table 4 and Figure 2, respectively.

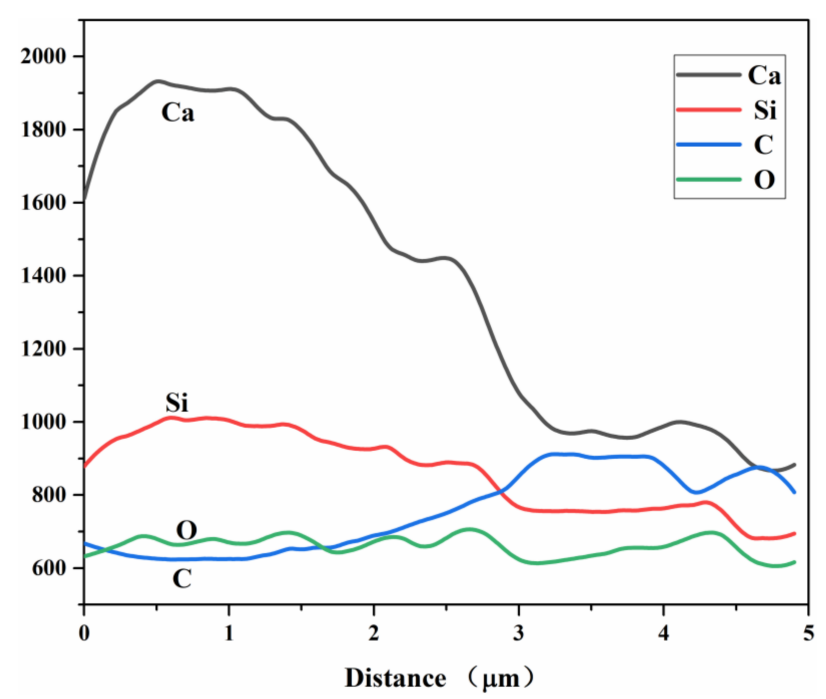

Figure 2. Energy dispersive spectrometer (EDS) line analysis results of autolytic microspheres. 
The results in Table 5 show that point 1 is cement clinker particles with a mass ratio of calcium to silicon equaling to 4.39 . Point 2 is the boundary between the darkest material edge and the surrounding hydration product, the mass ratio of carbon element increases while the mass of calcium silicon ratio decreased to 4.14. In addition, mass ratio of the carbon element takes up more than $60 \%$ in Point 3 while the mass ratio of the oxygen element also improves significantly compared with other two positions. Therefore, the dark region is indeed the PVP film layer due to the chemical composition of PVP mainly consisting of carbon and oxygen elements. The results shown in Figure 2 show that the relative content of $\mathrm{Ca}$ and $\mathrm{Si}$ elements in the position of the protective film layer from the autolytic microspheres to the marginal PVP film are decreasing in sequence, while the relative content of $\mathrm{C}$ and $\mathrm{O}$ elements are increasing in sequence. The results also prove that the protective effect of PVP protection film can be achieved.

Table 5. Mass Distribution of Major Elements in Different Regions.

\begin{tabular}{ccccc}
\hline Element Weight $\%$ & Ca & Si & C & O \\
\hline Point 1 & 37.01 & 8.44 & 11.43 & 43.12 \\
Point 2 & 17.07 & 4.12 & 45.08 & 33.14 \\
Point 3 & 9.69 & 2.34 & 62.27 & 25.07 \\
\hline
\end{tabular}

Figure 3 shows the FTIR spectra results of the only PVP system, the only clinker system and the clinker/PVP autolytic microsphere system. In the present study [33,34], the IR band at $1288 \mathrm{~cm}^{-1}$ and $1421 \mathrm{~cm}^{-1}$ of the only PVP system are assignable to $\mathrm{C}-\mathrm{N}$ stretching and $\mathrm{CH}_{2}$ bending vibration, respectively. The strong $\mathrm{C}=\mathrm{O}$ stretching vibration at $1670 \mathrm{~cm}^{-1}$ is also observed, which is the most significant characteristic vibration of PVP. The strong vibration of the only clinker system at $520 \mathrm{~cm}^{-1}$ and $925 \mathrm{~cm}^{-1}$ may correspond to the out-of-plane bending and anti-symmetrical stretching of $\mathrm{SiO}_{4}$ tetrahedra [35]. With respect to the spectra of the autolytic microsphere, strong bands-at $1670 \mathrm{~cm}^{-1}$ and $1421 \mathrm{~cm}^{-1}$-are observed. This may explain that clinker was successfully coated with PVP film. Furthermore, the characteristic vibration of clinker at $925 \mathrm{~cm}^{-1}$ and $520 \mathrm{~cm}^{-1}$ can be clearly found in autolytic microsphere system. This confirms that clinker remains the original mineral healing composition with the coating of PVP film on the clinker surface.

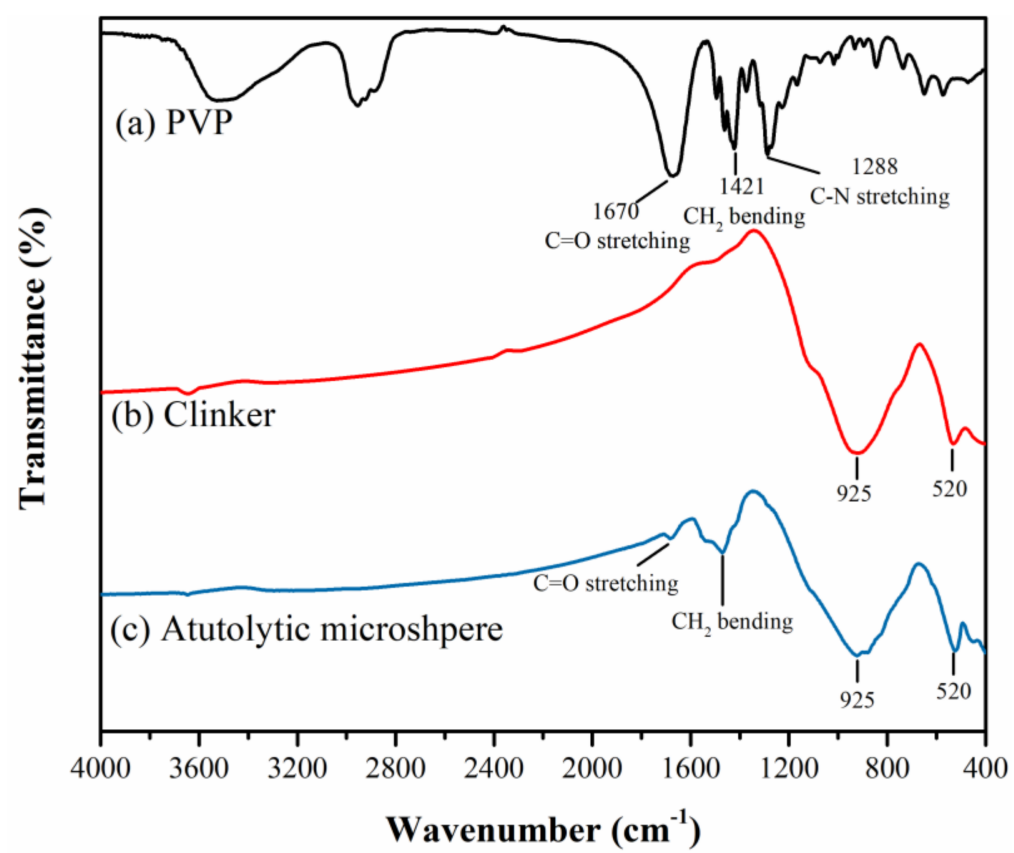

Figure 3. Fourier transform infrared spectroscopy (FTIR) spectra of (a) PVP (polyvinyl pyrrolidone), (b) clinker, (c) clinker/PVP autolytic microsphere. 


\subsubsection{Coating Film Thickness and Size Distribution}

The particle size distribution of the clinker/PVP microsphere is shown in Figure 4. The results in Figure 4 show that the particle size first shifts to the larger ones as the $\mathrm{PVP} / \mathrm{clinker}$ ratio increases from $0 \%$ to $4 \%$, and then the size shifts to the smaller ones as the PVP/clinker ratio increases to $15 \%$. This is mainly due to the increase in the viscosity of the stirring solution with the increasing amount of coating materials. The dispersion degree of the solution decreases once the critical amount is exceeded. In addition, all autolytic microspheres present a similar size distribution to clinker, each having sizes on the order of tens of microns. This means that addition of the clinker/PVP autolytic microsphere will not affect the particle accumulation of the ordinary matrix. This is an outstanding advantage when cement is replaced with autolytic microsphere. Based on the particle size distribution results, the average film thickness is calculated as shown in Table 6. The maximum thickness of coating film reaches at $7.54 \mu \mathrm{m}$ in the $\mathrm{PVP} / \mathrm{clinker}$ ratio of $4 \%$.

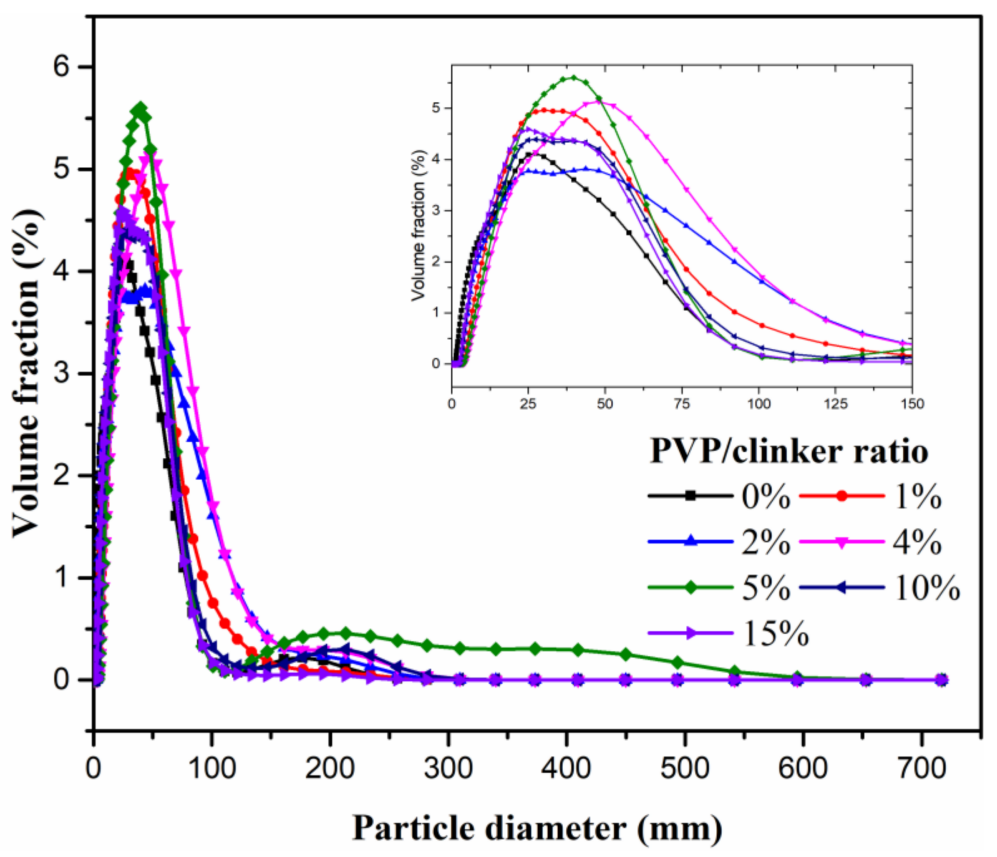

Figure 4. Particle size distribution of autolytic microspheres with different PVP/clinker ratio.

Table 6. The mean diameter and average film thickness of autolytic microspheres.

\begin{tabular}{cccccccc}
\hline Description & No. 1 & No. 2 & No. 3 & No. 4 & No. 5 & No. 6 & No. 7 \\
\hline PVP/clinker ratio & $0 \%$ & $1 \%$ & $2 \%$ & $4 \%$ & $5 \%$ & $10 \%$ & $15 \%$ \\
Mean diameter $(\mu \mathrm{m})$ & 21.05 & 27.20 & 27.50 & 36.12 & 32.54 & 26.16 & 24.62 \\
Average film thickness $(\mu \mathrm{m})$ & 0 & 3.08 & 3.23 & 7.54 & 5.75 & 2.56 & 1.79 \\
\hline
\end{tabular}

\subsubsection{Autolytic Behavior Analysis}

The control of autolytic behavior is important to avoid the premature consumption of microsphere which means enough autolytic time is needed [25]. Thus, the heat evolution of the clinker and autolytic microsphere paste were determined, and the results are shown in Figure 5. The hydration exothermic peak time of clinker appears at 444min. The autolytic time of clinker/PVP microspheres with $0 \mathrm{~g}, 1 \mathrm{~g}$, $3 \mathrm{~g}$ and $5 \mathrm{~g}$ silane coupling agent are calculated as $317 \mathrm{~min}, 728 \mathrm{~min}, 1193 \mathrm{~min}$ and $1420 \mathrm{~min}$ according to equation (2), respectively. In terms of autolytic time, the clinker without pretreatment (i.e., with $0 \mathrm{~g}$ silane coupling agent) is much less than that of the clinker with pretreatment. The autolytic time of clinker with only $1 \mathrm{~g}$ silane coupling agent presents $130 \%$ higher than that of SCA-0 sample, which means the pretreatment process is necessary to control the autolytic behavior of the clinker/PVP 
autolytic microsphere. In addition, autolytic time of microspheres get higher with increase in silane coupling agent amount. Experimental results show that the autolytic time can be controlled by the preparation process to meet different engineering requirements.

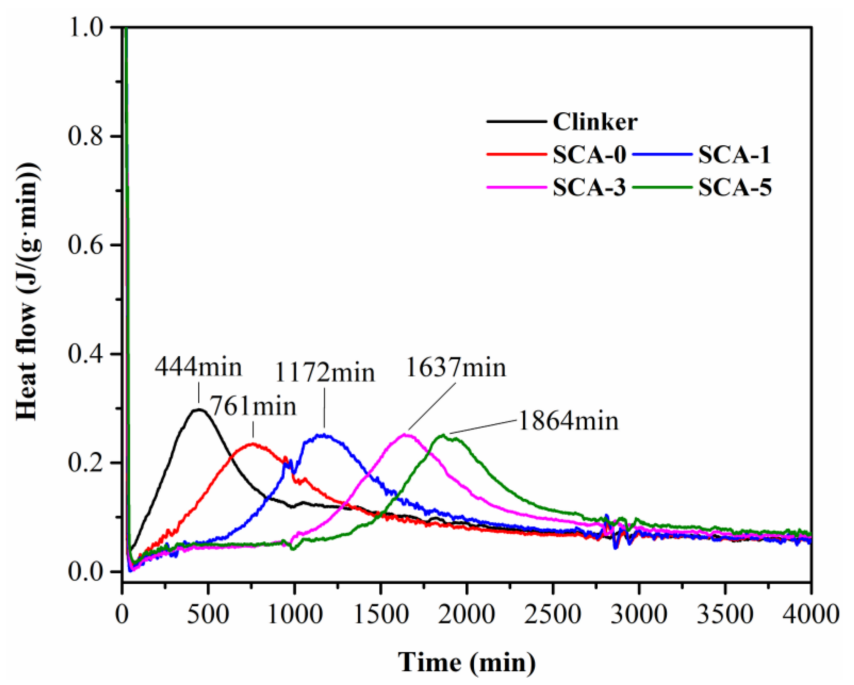

Figure 5. Heat evolution of clinker and microsphere paste with w/c ratio of 0.35 measured by isothermal calorimetry.

\subsection{Self-Healing Effectiveness of Specimen with Microsphere Prepared}

\subsubsection{Recovery of Compressive Strength}

The compressive strength is the main basis for quality control in civil engineering. Thus, compressive strength recovery is chosen as one of the evaluation methods for self-healing effectiveness. The clinker/PVP autolytic microsphere with a $7.54 \mu \mathrm{m}$ film thickness was adopted in the cement paste specimen. The compressive strength recovery of the specimen at 2 days, 14 days and 28 days after pre-crack is shown in Figure 6.

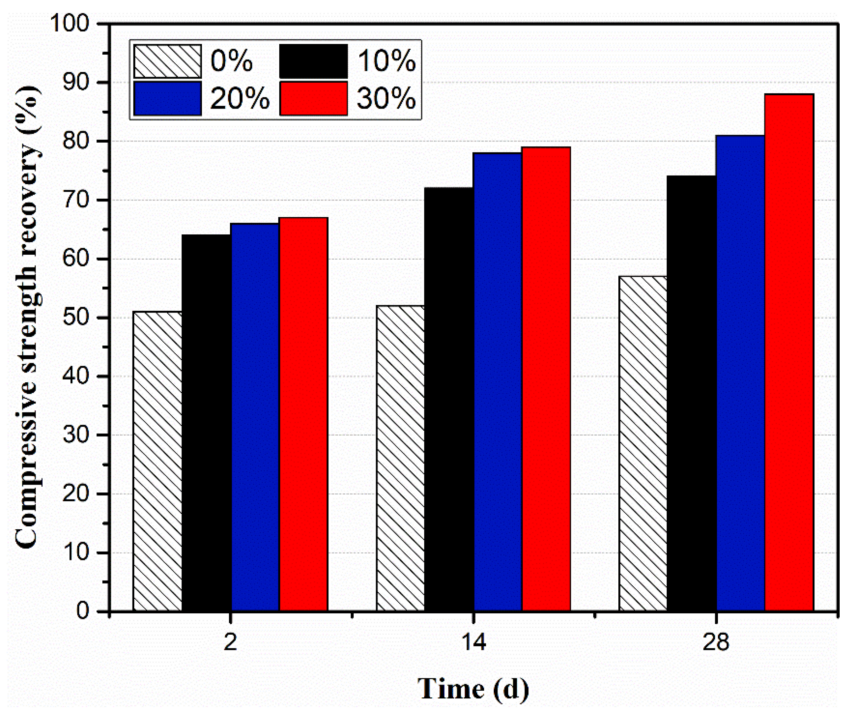

Figure 6. Compressive strength recovery at different curing time.

Results show that the compressive strength recovery of all the specimen-incorporating microspheres were higher than ordinary group at 2 days, 14 days and 28 days. The ordinary group of specimens-those not incorporating autolytic microspheres-have limited self-healing 
potential in terms of $51 \%$ compressive strength recovery at 2 days, and only $6 \%$ improvement from 2 days to 28 days. The specimens incorporating microspheres show more obvious self-healing ability. The compressive strength recovery rates of those specimens with microspheres were in the range of $64 \%-67 \%, 72 \%-79 \%$, and $74 \%-88 \%$ at 2 days, 14 days and 28 days, respectively. Moreover, the compressive strength recovery of specimens with $30 \%$ microspheres shows more improvement from 2 days to 28 days compared with the left two groups. Concerning the healing mechanism [19,36], this is due to more unhydrated clinker provided by clinker/PVP autolytic microsphere. On the other hand, compressive strength recovery of specimens with a 30\% microsphere reaches the maximum of $88 \%$ at the age of 28 days, which is $54 \%$ higher than that of ordinary cement paste specimens. Ongoing hydration is conducive to crack healing in autogenous self-healing cementitious materials. Experimental results confirm that self-healing properties is enhanced due to higher unhydrated clinker encouraged by the clinker/PVP microsphere.

\subsubsection{Recovery of Damage Degree}

To evaluate the internal closure recovery, damage degree was measured based on the ultrasound pulse time [37]. The damage degree will decrease once the internal crack closure is achieved. The effect of microsphere amount on damage degree is shown in Figure 7. Results show that the damage degree of the specimens with the microsphere decreased on elapsed time compared with the ordinary group. The damage degree of ordinary kept almost constant for 28 days. This means there was no significant internal crack healing in this group, which is consistent with the compressive strength recovery results. The damage degree of specimens with autolytic microspheres experienced a significant decrease, especially in those groups with $20 \%$ and $30 \%$ microspheres at the age of 28 days. These two groups even fell below the zero-standard line, which may be due to further microcrack healing besides the crack induced by pre-compression. Combined with the results of compressive strength recovery, the healing effectiveness may have more effect on permeability rather than on compressive strength.

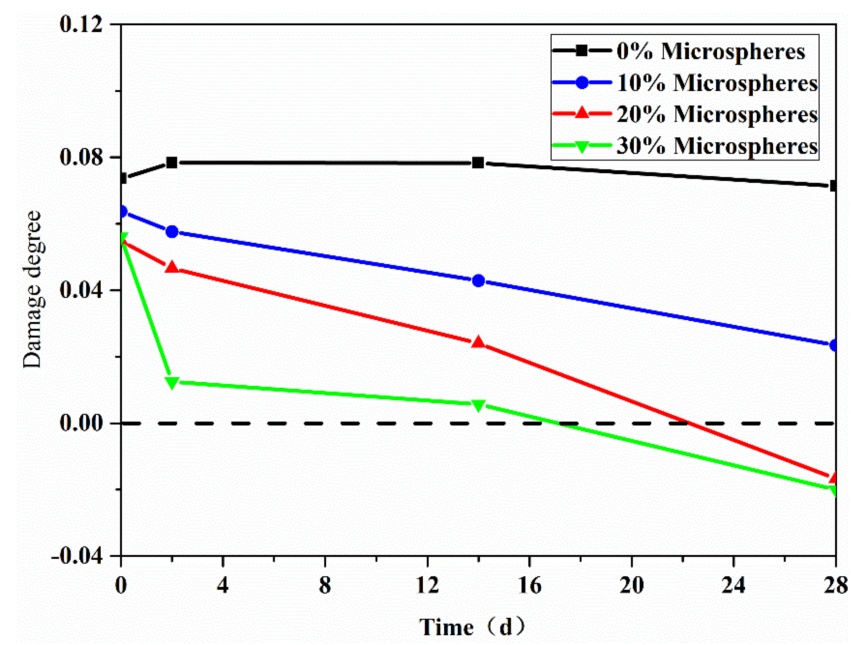

Figure 7. Effect of microsphere amount on damage degree.

\section{Conclusions}

In this paper, a clinker/PVP autolytic microsphere is proposed. A study on the preparation and characterization of autolytic microspheres is presented. The self-healing effectiveness of specimens with autolytic microspheres is also evaluated. Several conclusions can be obtained from the experimental results:

- $\quad$ The clinker/PVP autolytic microsphere is successfully prepared, and the self-healing potential is confirmed via the chemical structure measured by FTIR. 
- The film coating thickness increases first and then decreases with the increasing usage of coating materials, since there exists the optimal viscosity of solution. The maximum film thickness was $7.54 \mu \mathrm{m}$ in the PVP/clinker ratio of $4 \%$.

- The autolytic behavior of the clinker/PVP autolytic microsphere is successfully controlled by pretreatment degree (i.e., silane coupling agent amount).

- The self-healing potential of specimens with autolytic microspheres improves with an increase in the microsphere amount.

- The self-healing effectiveness of clinker/PVP autolytic microspheres is confirmed by the compressive strength recovery and damage degree tests.

Author Contributions: Conceptualization, Z.J. and W.L.; writing—original draft preparation, J.L.; writing—review and editing, Z.J. and J.L. All authors have read and agreed to the published version of the manuscript.

Funding: This research was funded by National Key Research and Development Projects (2018YFC0705404), National Natural Science Foundation of China (51878480, 51678442, 51878481, 51878496), National High-speed Train Union Fund (U1534207) and the Fundamental Research Funds for the Central Universities.

Conflicts of Interest: The authors declare no conflict of interest.

\section{References}

1. Wang, X.F.; Yang, Z.H.; Fang, C.; Han, N.X.; Zhu, G.M.; Tang, J.N.; Xing, F. Evaluation of the mechanical performance recovery of self-healing cementitious materials-Its methods and future development: A review. Constr. Build. Mater. 2019, 212, 400-421. [CrossRef]

2. Das, A.K.; Mishra, D.K.; Yu, J.; Leung, C.K.Y. Smart Self-Healing and Self-Sensing Cementitious Composites-Recent Developments, Challenges, and Prospects. Adv. Civ. Eng. Mater. 2019, 20190023, 1-25. [CrossRef]

3. Van Breugel, K. Self-healing material concepts as solution for aging infrastructure. In Proceedings of the 37th Conference on Our World in Concrete \& Structures, Singapore, 29-31 August 2012.

4. Van Tittelboom, K.; De Belie, N. Self-healing in cementitious materials-a review. Materials. 2013, 6, 2182-2217. [CrossRef] [PubMed]

5. Huang, H.; Ye, G.; Qian, C.; Schlangen, E. Self-healing in cementitious materials: Materials, methods and service conditions. Mater. Des. 2016, 92, 499-511. [CrossRef]

6. Sangadji, S. Can Self-healing Mechanism Helps Concrete Structures Sustainable? Procedia Eng. 2017, 171, 238-249. [CrossRef]

7. Li, C.; Wu, M.; Chen, Q.; Jiang, Z. Chemical and mineralogical alterations of concrete subjected to chemical attacks in complex underground tunnel environments during 20-36 years. Cem. Concr. Compos. 2018, 86, 139-159. [CrossRef]

8. Murakami, T.; Ahn, T.H.; Hashimoto, T.; Ogura, N.; Kishi, T. A study on the new water leak repair method for subway tunnels using crack self-healing repair materials. J. Ceram. Process. Res. 2015, 16, 95-97.

9. Li, V.C.; Herbert, E. Robust Self-Healing Concrete for Sustainable Infrastructure. J. Adv. Concr. Technol. 2012, 10, 207-218. [CrossRef]

10. He, J.; Shi, X. Developing an abiotic capsule-based self-healing system for cementitious materials: The state of knowledge. Constr. Build. Mater. 2017, 156, 1096-1113. [CrossRef]

11. Ren, Q.; Zeng, Z.; Jiang, Z.; Li, H. Functionalization of renewable bamboo charcoal to improve indoor environment quality in a sustainable way. J. Clean. Prod. 2020, 246C, 119028. [CrossRef]

12. Maes, M.; Snoeck, D.; De Belie, N. Chloride penetration in cracked mortar and the influence of autogenous crack healing. Constr. Build. Mater. 2016, 115, 114-124. [CrossRef]

13. Van Mullem, T.; Gruyaert, E.; Debbaut, B.; Caspeele, R.; De Belie, N. Novel active crack width control technique to reduce the variation on water permeability results for self-healing concrete. Constr. Build. Mater. 2019, 203, 541-551. [CrossRef]

14. Van Breugel, K. Is there a market for self-healing cement-based materials? In Proceedings of the First International Conference on Self Healing Materials, Noordwijk aan Zee, The Netherlands, 18-20 April 2007.

15. Yıldırım, G.; Khiavi, A.H.; Yeşilmen, S.; Şahmaran, M. Self-healing performance of aged cementitious composites. Cem. Concr. Compos. 2018, 87, 172-186. [CrossRef] 
16. Wu, M.; Johannesson, B.; Geiker, M. A review: Self-healing in cementitious materials and engineered cementitious composite as a self-healing material. Constr. Build. Mater. 2012, 28, 571-583. [CrossRef]

17. Tang, W.; Kardani, O.; Cui, H. Robust evaluation of self-healing efficiency in cementitious materials-A review. Constr. Build. Mater. 2015, 81, 233-247. [CrossRef]

18. Schlangen, E.; Sangadji, S. Addressing infrastructure durability and sustainability by self healing mechanisms-Recent advances in self healing concrete and asphalt. Procedia Eng. 2013, 54, 39-57. [CrossRef]

19. Li, W.; Dong, B.; Yang, Z.; Xu, J.; Chen, Q.; Li, H.; Xing, F.; Jiang, Z. Recent advances in intrinsic self-healing cementitious materials. Adv. Mater. 2018, 1705679, 1-9. [CrossRef]

20. Li, W.; Zhu, X.; Zhao, N.; Jiang, Z. Preparation and properties of melamine urea-formaldehyde microcapsules for self-healing of cementitious materials. Materials 2016, 9, 152-168. [CrossRef]

21. Li, W.; Jiang, Z.; Yang, Z. Acoustic characterization of damage and healing of microencapsulation-based self-healing cement matrices. Cem. Concr. Compos. 2017, 84, 48-61. [CrossRef]

22. Li, C.; Zhu, H.; Wu, M.; Wu, K.; Jiang, Z. Pozzolanic reaction of fly ash modified by fluidized bed reactor-vapor deposition. Cem. Concr. Res. 2017, 92, 98-109. [CrossRef]

23. Jiang, Z.; Li, W.; Yuan, Z. Influence of mineral additives and environmental conditions on the self-healing capabilities of cementitious materials. Cem. Concr. Compos. 2015, 57, 116-127. [CrossRef]

24. Dong, B.; Wang, Y.; Fang, G.; Han, N.; Xing, F.; Lu, Y. Smart releasing behavior of a chemical self-healing microcapsule in the stimulated concrete pore solution. Cem. Concr. Compos. 2015, 56, 46-50. [CrossRef]

25. Jiang, Z.; Li, J.; Li, W. Preparation and characterization of autolytic mineral microsphere for self-healing cementitious materials. Cem. Concr. Compos. 2019, 103, 112-120. [CrossRef]

26. Lee, Y.S.; Ryou, J.S. Self healing behavior for crack closing of expansive agent via granulation/film coating method. Constr. Build. Mater. 2014, 71, 188-193. [CrossRef]

27. Liu, W.; Roos, Y.H.; Fan, F. Physicochemical properties and relaxation time in strength analysis of amorphous poly (vinyl-pyrrolidone) and maltodextrin: Effects of water, molecular weight, and lactose addition. J. Food Eng. 2018, 226, 82-95. [CrossRef]

28. Naghdi Sedeh, N.; Entezam, M.; Hassan Jafari, S.; Khonakdar, H.A.; Abdouss, M. Morphology, drug release behavior, thermal, and mechanical properties of poly(ethylene oxide) (PEO)/poly(vinyl pyrrolidone) (PVP) blends. J. Appl. Polym. Sci. 2018, 135, 1-9. [CrossRef]

29. Malhotra, B.; Keshwani, A.; Kharkwal, H. Natural polymer based cling films for food packaging. Int. J. Pharm. Pharm. Sci. 2015, 7, 10-18.

30. Princigallo, A. Elastic and self-healing properties of concrete including graded clinker. ACI Mater. J. 2018, 115, 761-768. [CrossRef]

31. Zhong, W.; Yao, W. Influence of damage degree on self-healing of concrete. Constr. Build. Mater. 2008, 22, 1137-1142. [CrossRef]

32. Wang, P.; Feng, S.; Liu, X. Application of Backscattered Electron Imaging and Image Analysis in Microstructure Research on Cement-Based Materials. J. Chinese Silic. Soc. 2011, 39, 1659-1665.

33. Wu, C.; Mosher, B.P.; Lyons, K.; Zeng, T. Reducing ability and mechanism for polyvinylpyrrolidone (PVP) in silver nanoparticles synthesis. J. Nanosci. Nanotechnol. 2010, 10, 2342-2347. [CrossRef] [PubMed]

34. Usman, R.; Mihata, A.; Kurawaki, J. Rapid synthesis and characterization of polyvinylpyrrolidone-protected silver nanoparticles by heating method. e-Journal Surf. Sci. Nanotechnol. 2015, 13, 431-434. [CrossRef]

35. Stoch, A.; Zdaniewicz, M.; Paluszkiewicz, C. The effect of polymethylsiloxanes on hydration of clinker phases. J. Mol. Struct. 1999, 511-512, 319-325. [CrossRef]

36. Alghamri, R.; Kanellopoulos, A.; Al-Tabbaa, A. Impregnation and encapsulation of lightweight aggregates for self-healing concrete. Constr. Build. Mater. 2016, 124, 910-921. [CrossRef]

37. Xu, J.; Yao, W. Multiscale mechanical quantification of self-healing concrete incorporating non-ureolytic bacteria-based healing agent. Cem. Concr. Res. 2014, 64, 1-10. [CrossRef]

(C) 2020 by the authors. Licensee MDPI, Basel, Switzerland. This article is an open access article distributed under the terms and conditions of the Creative Commons Attribution (CC BY) license (http://creativecommons.org/licenses/by/4.0/). 